\title{
Physical activity and sport in patients with cardiac diseases
}

\author{
Hrvoje Pintarić* \\ University Hospital Centre "Sestre milosrdnice", Zagreb, Croatia
}

In the last 15 years, many epidemiological studies have shown an unequivocal and robust relationship of fitness, physical activity, and exercise to reduce overall and cardiovascular disease (CVD) mortality. Up to $80 \%$ of heart disease, stroke and type 2 diabetes mellitus could be prevented by eliminating obesity, unhealthy diets and physical inactivity. Meta-analyses provide strong evidence that exercise-based cardiac rehabilitation reduces mortality in coronary artery disease (CAD) patients, but the absence of a sufficiently powered, randomized clinical trial prohibits absolute certainty that exercise training alone reduces cardiac mortality in CAD patients. Exercise training is underused as a therapeutic modality but can easily be prescribed for most patients by referral to a cardiac rehabilitation program or by recommending walking to the onset of dyspnea. Despite these benefits, exercise training is rarely prescribed for cardiac patients, as evidenced by the fact that only $\approx 20 \%$ of qualified patients are referred to formal cardiac rehabilitation programs. Referral rates are even lower among women and elderly patients. The reasons for this underutilization are not defined, but probably include health professionals' underestimation of the benefits of exercise, a lack of training in exercise therapeutics among many healthcare providers, poor financial reimbursement and the absence of reimbursed advocates for exercise therapy. Sexual activity is an important component of patient and partner quality of life for men and women with CVD, including many elderly patients. Sexual activity is the cause of $<1 \%$ of all acute myocardial infarctions. Men and women with stable CVD who have no or minimal symptoms during routine activities can engage in se- xual activity. This includes patients with (1) Canadian Classification System class 1 or 2 angina; (2) New York Heart Association (NYHA) class I or II heart failure; (3) mild to moderate valvular disease; (4) no symptoms after MI; (5) successful coronary revascularization; (6) most types of congenital heart disease (CHD); and (7) ability to achieve 3 to 5 METS during exercise stress testing without angina, ischemic electrocardiographic changes, hypotension, cyanosis, arrhythmia, or excessive dyspnea. Patients with unstable, decompensated, and/or severe symptomatic CVD should defer sexual activity until their condition is stabilized and optimally managed.

KEYWORDS: physical activity, sport, cardiac diseases. CITATION: Cardiol Croat. 2013;8(9):319.

\section{Received: 26 $6^{\text {th }}$ Jun 2013}

*Address for correspondence: Klinički bolnički centar "Sestre milosrdnice", Vinogradska 29, HR-10000 Zagreb, Croatia.

Phone: +385-99-3787-147

E-mail: hrvojepintaric@yahoo.com

\section{Literature}

1. Thompson PD. Exercise prescription and proscription for patients with coronary artery disease. Circulation. 2005;112:2354-63.

2. Perk J, Veress G. Cardiac rehabilitation: applying exercise physiology in clinical practice. Eur J Appl Physiol. 2000;83:457-62.

3. Levine GN, Steinke EE, Bakaeen FG, et al. Sexual activity and cardiovascular disease: a scientific statement from the American Heart Association. Circulation. 2012;125:105872. 